\title{
EN LAS ENTRAÑAS DEL CAIMÁN \\ La simbología del caimán en la arqueología
}

\section{IN THE BOWELS OF THE CAIMAN}

The symbolism of the caiman in archaeology

\section{Arturo Cifuentes Toro*}

\begin{abstract}
Resumen
Se trata de mostrar en el artículo la importancia que representa para la cultura monolítica la imagen de saurios o lagartos. Si bien es cierto que otras imágenes animales llamaron la atención de arqueólogos e historiadores centrando el foco de atención en el jaguar, la serpiente, el águila, entre otros. La presencia del caimán en las esculturas agustinianas indica un culto al animal que abundaba en el Magdalena. Observando los dibujos desdoblados de las esculturas de San Agustín, elaborados por Velandia (1994), vemos los afilados colmillos del animal, similares a los puntiagudos dientes del jaguar. Y nos sorprende además uno de los resultados obtenidos por Velandia en la parte posterior de la escultura «después de reconstruir lo des-armado fue un taimado caimán que nos mira de frente».
\end{abstract}

Palabras clave: estatuaria, caimán, cultura monolítica, escultura, iconografía.

\begin{abstract}
This article tries to show the importance that the image of saurian creatures have for the monolithic culture of San Agustín. If it is true that other animal images caught the attention of archaeologists and historians, such as the jaguar, the serpent, the eagle, among others; the presence of the caiman in the Augustinian sculptures indicates a cult to this animal that abounded in the Magdalena River. By observing the unfolded drawings of the sculptures of San Agustin, prepared by Velandia (1994), we see the sharp fangs of the animal, similar to the pointed teeth of the jaguar. And also one of the results obtained by Velandia on the back side of the sculpture, surprised us "after rebuilding the des-armed, we saw it was a devious caiman that was looking right at us"
\end{abstract}

Key words: statues, caiman, monolithic culture, sculpture, iconography.

Un indígena chimila soñó con un caimán al que le quitó un huevo cuando andaba por la playa del río Magdalena, después de consumir el óvulo sintió terror. La gente le decía que no tuviera miedo, por cuanto el caimán era gente parecida a ellos, pero el nativo mantenía su temor a ser devorado por el saurio, hasta que llegó el día en que fue con su hermano al río y se le materializó el sueño, siendo devorado por el reptil, que lo tragó con arco y flecha. Cuando el hombre se encontraba en el vientre del caimán, sintió hambre, sed, y deseos de ver la luz.

Artículo recibido: 15/05/2013 Aprobado: 28/06/2013

* Antropólogo Universidad Nacional de Colombia. Magíster en Historia Pontificia Universidad Javeriana. El presente artículo hace parte del texto inédito. Yuma la recuperación de la memoria. Email: cifuentestoro@yahoo.com 
El Caimán, molesto salió de su cueva y exclamó; ¿Quién me está chuzando? El nativo prosiguió con su actuar, volviendo casi loco al saurio que se vio obligado a toser, abriendo su gran boca, momento que aprovechó el hombre trancándola con la flecha y salir casi muerto. Decaído y enfermo el indígena resolvió ir al monte a recuperarse.

Después volvió al poblado gordo, con cacería en su mochila, traía mono, tatabro, guatinaja, danta, zaino. Inquietos los demás indígenas por su suerte lo siguieron queriendo conocer el truco de la cacería, y viendo que al silbar acudían los monos, y los otros animales se sorprendieron. Cuando le preguntaron por el secreto, les contó que lo había aprendido del caimán cuando estuvo en su vientre ${ }^{1}$. El mito anotado por Reichel-Dolmatoff, alude de acuerdo al investigador a la situación de los chamanes esqueleteados y a la figura arquetípica de un hombre tragado por un monstruo acuático que sale «regresa», de un estado de purificación y sabiduría.

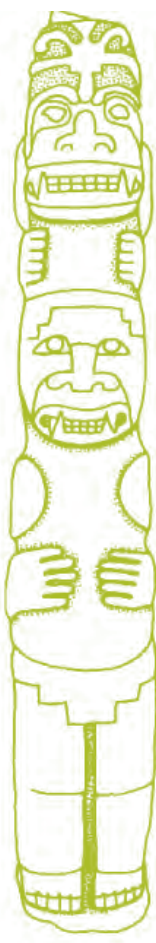

FRENTE

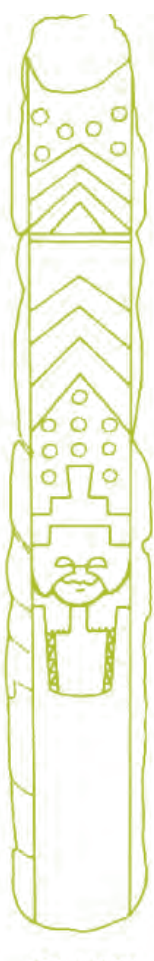

POSTERIOR

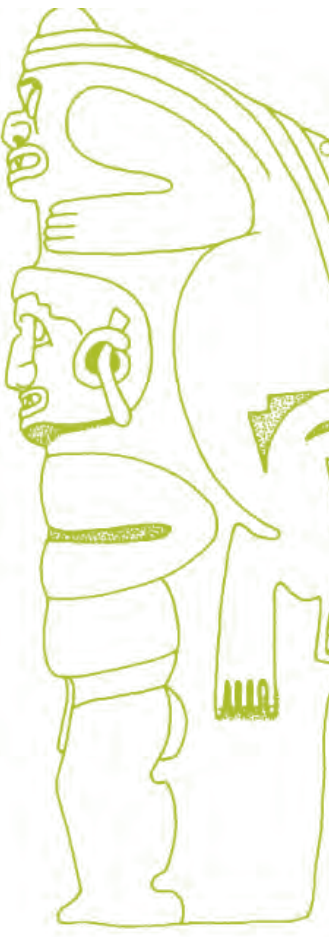

LATERAL
Reichel-Dolmatoff, además en su estudio sobre la orfebrería, alusiva a los vuelos chamánicos encuentra un adorno en el cual se aprecia la cabeza de un hombre en el vientre del animal'2. En otros mitos suramericanos se leen relatos semejantes, como el del entorno al origen de los hornos, analizado por Lévi-Strauss, donde un hombre encolerizado contra el fuego que había quemado a su sobrino, le ordena a su hermana que preparara el horno para acostarse sobre las piedras que lo asaron, hecho lo cual se levantó y marcha al río, desapareció en el agua convertido en caimán. Tiempo después retornó indemne, sin rastros del suplicio.

Como evidencias mostró los pececillos que traía atrapados en la larga cabellera, enseñó a los indios los cantos rituales que había aprendido entre los peces y repartió entre las diferentes casas, los nombres ceremoniales llamados «de peces» que acostumbran usar los kayapos ${ }^{3}$. El regreso al mundo como lo anotó ReichelDolmatoff está lleno de saberes y experiencias, situación no común a las gentes, en cambio es propia de chamanes y héroes culturales.

En la iconografía de estatuaria, orfebrería aparece el peligroso caimán. Cesar Velandia uno de los estudiosos de la iconografía de San Agustín anota que las representaciones de saurios o lagartos no son un hecho aislado en la iconografía del Macizo Andino. Velandia considera, que la reiteración que tiene el uso de las figuras del jaguar, la serpiente y el águila como «culto solar» desplazó en su momento a otras formas de representación animal, cuestión plenamente verificable con una observación más detallada 4 .

En la estatuaria agustiniana el saurio se encuentra plasmado en variados diseños, estilizado con dientes demasiado cuadrados (sin mostrar agresión. (Figura, Núm. 279 Sotomayor y Uribe) igualmente se encontró en la tumba excavada por Duque y Cubillos en la Mesita B (catálogo, Núm. 282). En la estatuaria también se aprecia como un manto que cae o es la cabeza «doble yo» (Núm. 136). En

1. Reichel-Dolmatoff, Mitos y cuentos de los indios chimilas. Boletín de arqueología Núm. 1, Bogotá, 1945. p. 16.

2. Reichel-Dolmatoff, Orfebrería y chamanismo, Colima Ltda., Bogotá, 1988, p. 74.

3. Drayfus, En Levi-Strauss, El hombre desnudo. Siglo XXI, 1997, pp. 554-555.

4. Velandia Cesar. San Agustín: Arte, estructura y arqueología. Biblioteca Banco Popular. Bogotá, 1994. 

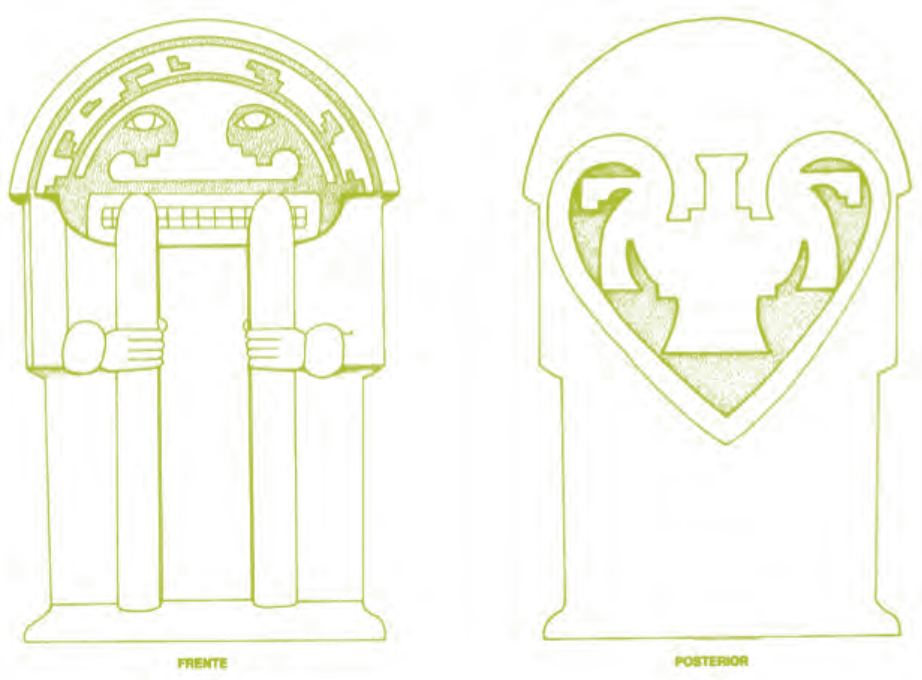

el Alto de los Ídolos, Preuss encontró estatuas caídas entre ellas una monumental (Catálogo Núm. 289)5.

En la investigación adelantada por el profesor Cesar Velandia en torno a la simbología de las estatuas de San Agustín, lo encuentra oculto, muy camuflado donde menos se esperaba. Recurriendo a un análisis estructural de la iconografía, al desdoblar los adornos de la cabeza de la estatua No 108 en un proceso de disección, casi se sintió devorado por el saurio.

El icono analizado por Velandia consiste de acuerdo al investigador «en una representación antropomorfa, ataviada con una especie de «sayón» que le cubre todo el cuerpo. Sobre la cabeza, ocultando la mayor parte de la cara aparece una máscara. En el envés de la losa, hacia la parte superior, ostenta un «ideograma» de forma muy compleja. El trabajo escultórico es apenas un relieve, como ocurre en gran parte de la estatuaria, pero a pesar del tratamiento planimétrico, la pieza tiene una proyección de volumen que fue lograda mediante recursos del dibujo. Los brazos están flexionados sobre el vientre, en las manos sostiene respec- tivamente dos instrumentos, cuyos extremos cubren parcialmente la parte inferior de la máscara. Un detalle que estimo importante es el de la nítida distinción entre la planimetría de los elementos de la máscara y la proyección volumétrica y realista de los ojos.... $\nu^{6}$. El meticuloso proceso quirúrgico se encuentra en su libro San Agustín. Arte, estructura y arqueología. Uno de los resultados obtenidos por Velandia en la parte posterior de la escultura «después de reconstruir lo desarmado fue un taimado caimán que nos mira de frente»

La presencia del caimán en las esculturas agustiniana indica un culto al animal que abundaba en el Magdalena. En la mitología de algunos grupos indígenas corresponde al dueño de las aguas, entre los warrau, de la Guyana se creía que además de ser el dueño de las aguas su misión es la de evitar que se erosione la tierra ${ }^{7}$. Observando los dibujos desdoblados de las esculturas de San Agustín, elaborados por el profesor Velandia, vemos los afilados colmillos del animal, similares a los puntiagudos dientes del jaguar.

El Jaguar se ha considerado figura emblemática de los chamanes, tema analizado por el arqueólogo Héctor Llanos ${ }^{8}$. La asociación jaguar, caimán en las estatuas agustinianas nos puede plantear situaciones simbólicas mantenidas por los sedentarios agustinianos, quienes sentían un profundo respeto por las selvas y los ríos.

Pero la asociación caimán jaguar se encuentra en la mitología suramericana. En el mito de los indígenas sherenté del origen del fuego por ejemplo, el jaguar dueño de la lumbre transporta al héroe cultural de la tribu por los arroyos que son propiedad de varios animales que no permite tomar agua, el jaguar busca por esto llegar al sitio del caimán, donde deposita al héroe que absorbe todo el líquido a pesar de

5. Sobre la problemática Agustiniana existe la mayor información arqueológica del país y su probable interpretación se puede localizar en su extensa bibliografía. Destacamos para los interesados las investigaciones adelantadas por Luis Duque Gómez, Julio Cubillos, Héctor Llanos y Robert Drenan que se pueden consultar en las publicaciones de la Fundación de Investigaciones Arqueológicas Nacionales, en las del ICAHN y Universidad de los Andes. Igualmente hay dos texto de importancia en cuanto a la simbología, escritos por César Velandia y Héctor Llanos.

6. Velandia, Op, cit, p. 36 .

7. Schaden, en Levi-Strauss, mitológicas I, p. 190.

8. Llanos Vargas Héctor. Los chamanes jaguares de San Agustín. 
la súplica del saurio. Estos nativos consideraban que el jaguar era el amo del fuego entre tanto el caimán lo era del agua. Lévi-Strauss analizado el mito sherenté observa que para volverse el héroe dueño del fuego ha hecho falta antes que él se ocupe del lugar del dueño del agua: aniquilándola, podría decirse, puesto que se la bebe del todo. Continua anotando que el héroe al ser transportado por el jaguar, pide agua para apaciguar su intensa sed la cual solo consigue en el arroyo del caimán, donde no deja ni una gota. El incidente anota el antropólogo se aclara gracias al mito de los kayuá donde argumentan que el caimán es el amo del agua y que tiene por misión impedir que se seque la tierra: «el yacaré es el jefe del agua para que no se seque todo el mundo» ${ }^{9}$.

Lévi-Strauss anota a propósito de algunos planteamientos hechos por los «tupinólogos» en torno a la pareja jaguar-cocodrilo (dueño del fuego, dueño del agua) quienes han juntado el nombre tupí del jaguar, iagua a la palabra yacaré que designa al cocodrilo y que podría analizarse como iagure-ré «la otra clase de jaguar» que no existiría ninguna equivalencia concebible entre las dos especies $^{10}$.

Otra perspectiva interesante es la ofrecida por los viajeros en el río Magdalena, al respecto de la disputa sostenida por el jaguar y el caimán. El inglés John Hanrshaw, en su viaje por el río, escribió que los tigres en algunas partes de las selvas del valle rara vez bajaban al río en el día y que atacaba poco al hombre a menos que fueran provocados, pero en cambio era un enemigo declarado del caimán «al que frecuentemente sorprende saltándole encima cuando este duerme en las orillas del río. Si el caimán es joven, lo más seguro es que muera, pero si es grande logra a veces correr con el tigre a cuestas y echarse al río donde los otros caimanes acuden en su defensa. Cuando un tigre quiere cruzar el río, antes de meterse en el agua lanza un tremendo rugido que hace dispersar inmediatamente a todos los caimanes, entonces lo atraviesa a salvo» ${ }^{11}$.

Además ese caimán también pelea con el Sol y es escultor. En un mito de los macushi se narra una disputa entre el astro y el saurio por los peces de un estanque. El sol confió la vigilancia del estanque al caimán, pero descubrió más tarde, en flagrancia, al saurio robando los peces, razón por la cual azotó su lomo, formándose las escamas. El caimán temiendo su muerte ofreció su hija al Sol con la esperanza de ser perdonado, sin embargo, el caimán no tenía hijas, por lo que fue necesario que esculpiese una figura femenina en el tronco de un ciruelo silvestre. El caimán dejó al sol la responsabilidad de arrimar a la figura y desapareció en el agua, esperando el resultado de su treta. En eso sigue desde entonces ${ }^{12}$.

\section{Referencias bibliográficas}

Hanrsihaw, Jhon. Crónica Grande del río de la Magdalena, En: Aníbal Mendoza Noguera, p. 260. Bogotá, 1980.

Lévi-Strauss. Mitológicas II, De la miel a las cenizas. México: Fondo de Cultura económica, 1978.

Lévi-Strauss. Mitológicas I, De lo crudo a lo cocido. México: Fondo de cultura económica, 1976.

Llanos, Héctor. Los chamanes jaguares de San Agustín, Génesis de un pensamiento mitopoético. Bogotá, 1995.

Mendoza Noguera, Aníbal. Crónica Grande del río de la Magdalena. Bogotá: Sol y Luna. 2 t., 1980.

Preuss, K. Th. Arte monumental prehistórico. Bogotá: Universidad Nacional, 1974.

Reichel-Dolmatoff, Gerardo. Orfebrería y chamanismo, Un estudio iconográfico del Museo del Oro. Bogotá: Colima, 1988.

Reichel-Dolmatoff, Gerardo. Mitos y cuentos de los indios chimilas. Bogotá: Boletín de arqueología No. 1.

Sotomayor, Lucía y Uribe, Victoria. Estatuaria en el Macizo Colombiano. Bogotá: Imprenta Nacional, 1987.

Velandia Jagua César. San Agustín: Arte, estructura y arqueología. Bogotá: Biblioteca Banco Popular, 1994.

9. Levi-Strauss Mitológicas I, p. 190.

10. Ibídem, nota p. 190.

11. John Hanrsihaw, En Aníbal Mendoza Noguera. Crónica Grande del río de la Magdalena, p. 260. Bogotá, 1980.

12. Levi-Strauss, Mitológicas II, p. 183. 